\title{
Experimental Investigation on Shear Failure Mechanism of Rock Mass with Intermittent Joints
}

\author{
Minghui Ma, ${ }^{1,2}$ Fenhua Ren ${ }^{(D)}{ }^{1}$ and Wensheng Liu ${ }^{1}$ \\ ${ }^{1}$ School of Civil and Resource Engineering, University of Science and Technology Beijing, Beijing 100083, China \\ ${ }^{2}$ Xilin Gol Shandong Gold Group A'erhada Minerals Co., Ltd., Xinlin Gol 026000, China \\ Correspondence should be addressed to Fenhua Ren; renfh_2001@163.com
}

Received 22 November 2020; Revised 24 February 2021; Accepted 10 March 2021; Published 17 March 2021

Academic Editor: Xun Xi

Copyright (c) 2021 Minghui Ma et al. This is an open access article distributed under the Creative Commons Attribution License, which permits unrestricted use, distribution, and reproduction in any medium, provided the original work is properly cited.

There are a large number of discontinuous weak planes distributed in the natural rock mass, which makes the sliding failure of rock mass along the intermittent structural plane very complex. To investigate the shear failure mechanism of rock mass with intermittent joints and study the influence of different joint heights on the shear failure mode of the rock mass, direct shear tests were carried out by presetting a series of jointed rock specimens with different undulating heights. During the shear loading, digital image correlation (DIC) technology was employed to monitor the surface strain field of the specimens in real time. The results show that the fluctuation height has a significant effect on the evolution of shear strain. With the increase of shear load, the maximum shear strain of the jointed specimens with different undulating heights first increases slowly and then increases rapidly. When the undulating height is $5 \mathrm{~mm}$, the failure of the specimen is dominated by the rock sliding along prefabricated joints. When the undulating height is larger than $10 \mathrm{~mm}$, the shear fracture of the rock becomes dominant. With the increase of the undulating height, more penetrating cracks perpendicular to the preexisting joints appear between the serrated surfaces, and the shear fracture phenomenon is more obvious.

\section{Introduction}

When a rock mass shears along a structural plane, the shear resistance of the structural plane is affected by the structural plane undulations and by the friction between the contact regions [1-3]. Intermittent joints are widely distributed in the rock mass for both slopes and underground spaces, and the mechanism of sliding failure caused by intermittent joints is often very complex [4-7]. Therefore, the research on the shear mechanical properties and deformation characteristics of discontinuity rock mass is one of the important scientific problems in the field of engineering geology and rock mechanics [8-10]. As early as 1969 , Lajtai $[11,12]$ studied the failure mode of jointed gypsum through direct shear test. He divided the failure mode of jointed gypsum into three types: tensile failure, shear failure, and compressive failure. Direct shear test is an effective method to study the effect of shear stress on jointed rock mass. It can simulate the stress state of jointed rock mass when it is destroyed in nature. In order to better control the increase of load, Gehle [13] has improved the ordinary direct shear test by using servo control system to change the shear rate. Zhu et al. [14] carried out numerical simulation on the fracture mode of rock specimens with prefabricated cracks under dynamic load and studied the failure process of rock specimens with different angles of prefabricated cracks under dynamic load. Yang et al. [15] carried out uniaxial compression test on fractured fine sandstone with different shapes and analyzed the influence of fracture on rock mass failure mode. The results show that the failure mode mainly includes tensile failure, shear failure, and combined tensile shear failure, which changes with the width of rock bridge. Yang et al. [16] carried out impact compression test on red sandstone and grey sandstone layered composite rock mass specimens by using the split Hopkinson compression bar (SHPB) test system. The test results show that the red sandstone mainly shows shear failure, and the failure of the part at the boundary layer legs other regions. For the gray sandstone, tensile failure is dominant and local shear failure occurs at a high impact velocity. As the shear failure mechanism of structural plane is more complex, numerical simulation as a scientific research method can 
effectively reflect the micro- and macromechanical properties of rock [17, 18]. Huang et al. [19] analyzed the failure mechanism of multiple cracks in rock by using RFPA software and combined it with existing research results and discussed the influence of spatial arrangement geometric characteristics, mechanical parameters, loading mode, and nonuniform factors of prefabricated cracks in rock on the stress field distribution, acoustic emission distribution, penetrative mode of rock bridge area, and breakthrough criterion in the evolution process.

As a complex engineering geological body, natural rock mass has a large number of discontinuities such as joints, fissures, and faults with different scales [20-22]. At present, the shear strength characteristics and deformation laws of two-dimensional regular structural plane are mainly studied by direct shear test [23-25]. Seidel et al. [26] carried out regular serrated structural plane shear test with concrete specimens and studied the variation of shear deformation with effective normal stress. Kwon et al. [27] used gypsum materials to make rectangular structural planes with different undulating heights, analyzed the relationship between shear strength and normal stress, bulge height, etc., and established a rigid structural plane model. Chen [28] used rock like materials to prepare models of discontinuous joint specimens, carried out uniaxial compression experiments on discontinuous joint specimens with different joint dip angles by servo press, and obtained five failure modes of joint specimens under the influence of joint angles. However, the researches about shear tests and shear failure of jointed rocks are not maturely understood and studied yet, which needs to be further investigated. With the advancement of experimental monitoring technology, it is possible to continuously track the entire process of rock failure by using the digital image correlation (DIC) technology [29-31]. The DIC method is a noncontact, high-precision full-field observation technology based on digital image technology. At present, this technology provides a useful tool for rock failure analysis. Many studies have used DIC technology to explore evolution of surface deformation fields [32], expansion of preexisting cracks [33, 34], and fracture process [35-37] of rocks during compression.

To study the shear mechanical properties of rock mass with different roughness discontinuities, rock specimens with regular dentate discontinuities with different undulating heights were made. Based on the direct shear test and the digital image correlation technology, the real-time monitoring of the surface strain field of the specimen during shearing tests is carried out. The shear strength, deformation, and other mechanical characteristics of the regular dentate structural plane with different undulating heights are analyzed, and the shear anisotropy characteristics and failure mode of the complex jointed rock are revealed.

\section{Test Schemes}

Considering the influence of joint undulation height on the shear mechanical properties of the specimen, the prepared specimens are shown in Figure 1. The size of the model is $100 \mathrm{~mm} \times 100 \mathrm{~mm} \times 30 \mathrm{~mm}$, and the fracture is penetrative. A total of 5 groups of periodic undulating fractures are set up, with undulating heights of $5 \mathrm{~mm}, 10 \mathrm{~mm}, 15 \mathrm{~mm}$, $20 \mathrm{~mm}$, and $30 \mathrm{~mm}$, respectively. The joint specimens with different undulating heights are marked as B-5, B-10, B-15, B-20, and B-30, respectively. The fracture is made by wire cutting along the side of the specimen. The jointed specimens with different undulation heights are shown in Figure 2. During shearing tests, the normal load value is $1 \mathrm{MPa}$ and is a constant.

The rock shear test machine (TFD-20H/50J, Changchun Keyi Test Instrument Co., Ltd.) was used in the test, with the maximum normal load of $20 \mathrm{KN}$ and the maximum tangential load of $50 \mathrm{KN}$. To record the deformation characteristics of the specimen during the shearing process, DIC equipment is used to monitor the surface deformation of the specimen. The layout of test equipment is shown in Figure 3(a). Among them, the digital camera is used to collect the speckle image of the specimen surface in the test process, the auxiliary lighting equipment is used to improve the image quality, and the deformation data of the specimen is collected at high frequency, and the postprocessing and matching analysis is carried out by professional operation optimization method. The test process is as follows: after the test piece is installed and fixed, start the DIC system, turn on the lighting, acquisition, and analysis system, and verify the calibration image quality. The data acquisition system runs synchronously with the mechanical testing machine. The shape, displacement, and deformation data of the specimen in full field and time domain were collected.

In the form of an artificial speckle pattern, a white primer is applied on the surface of the object, and then matte black spray paint is used for spraying or manual point drawing. The quality of speckle fabrication is related to the accuracy of strain field data in the compression test. In this test, two methods of spray painting and spot drawing are adopted. After the comparison and analysis of the corresponding variable field data, the spot drawing method is selected to make the speckle, as shown in Figure 3(b). The scattered spots with different sizes and uneven distribution are produced by manual point drawing. To track the variation characteristics of the strain field near the fracture, the density of speckle around the fracture is high.

\section{Test Results}

3.1. Shear Failure Mode. As shown in Figure 4, the failure modes of the penetrative joints with different undulating heights show significant differences with the fluctuation height. When the undulation height is only $5 \mathrm{~mm}$, the failure mode in the shear process is mainly the slip along the preset fracture. Shear damage occurs locally in the rock, but there is no obvious shear phenomenon in the serrated surface. When the height of undulation reaches $10 \mathrm{~mm}$, a significant shear fracture occurs at the end, and the peak shear load increases significantly. With the increase of the undulating height, several penetrative joints perpendicular to the preset joints are produced between the serrated surface, and the shear fracture phenomenon of the serrated surface is obvious. According to the shear load-displacement curve, there is a multistage shear change phenomenon after the shear peak. 


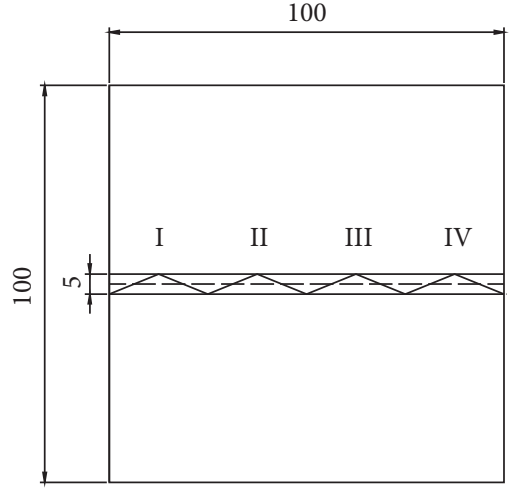

(a)

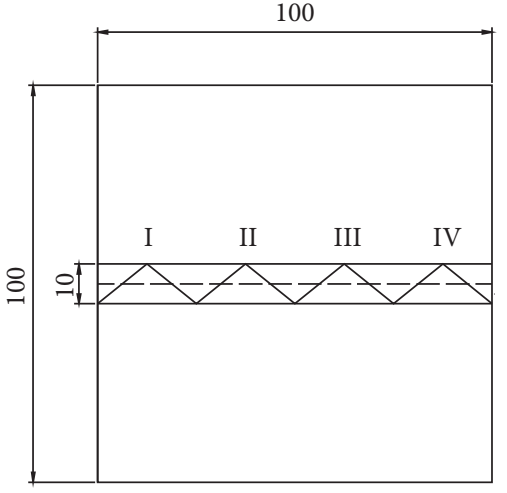

(b)

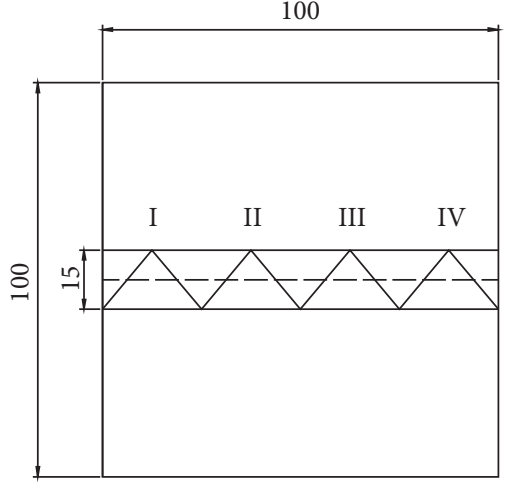

(c)

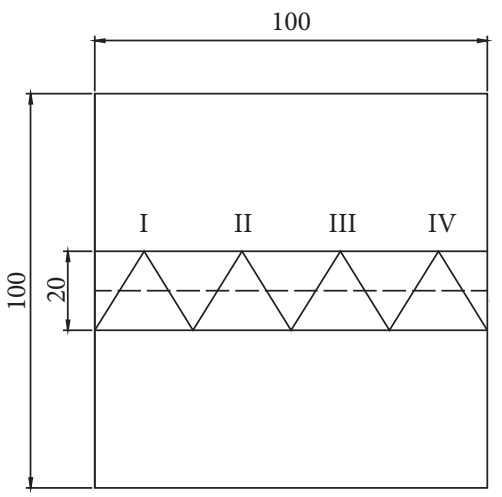

(d)

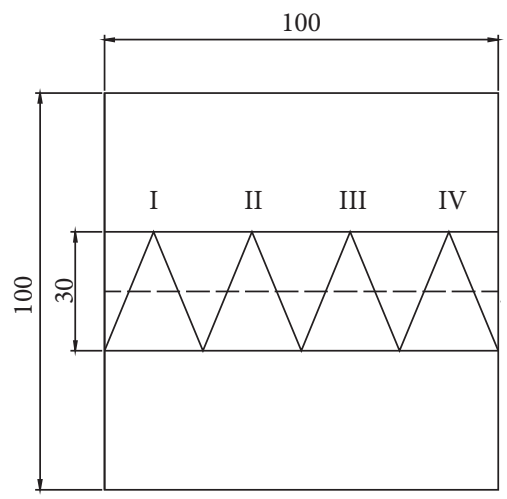

(e)

Figure 1: Schematic diagram of rock specimens with different undulating heights. (a) B-5. (b) B-10. (c) B-15. (d) B-20. (e) B-30.

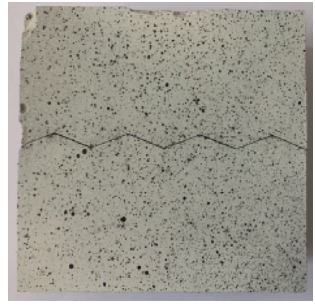

(a)

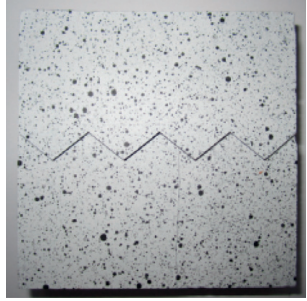

(b)

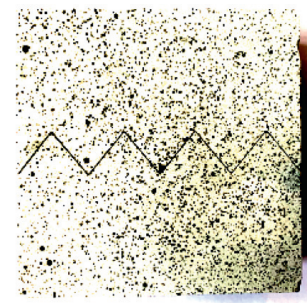

(c)

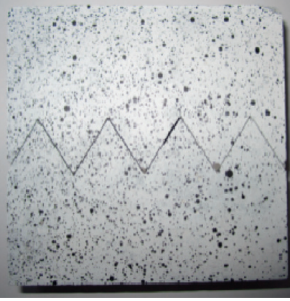

(d)

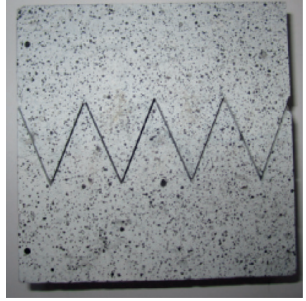

(e)

Figure 2: Specimens with different undulating heights. (a) B-5. (b) B-10. (c) B-15. (d) B-20. (e) B-30.

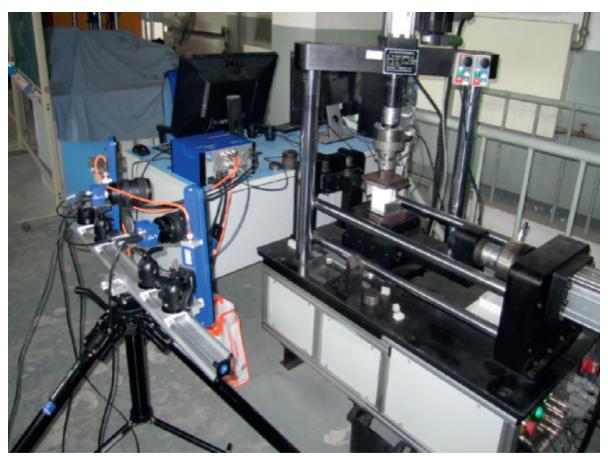

FIgUre 3: Direct shear test equipment with DIC. 


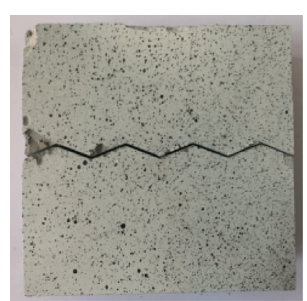

(a)

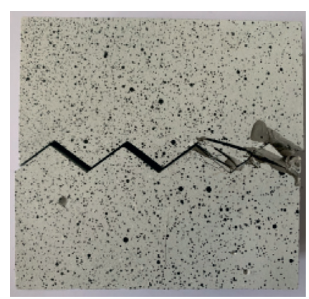

(b)

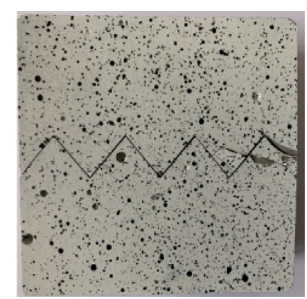

(c)

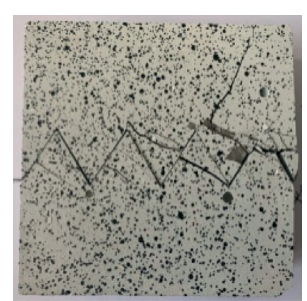

(d)

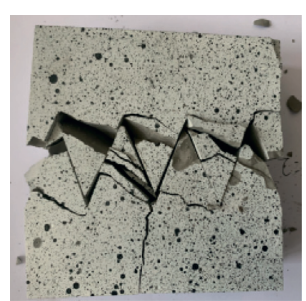

(e)

FIgURE 4: Failure modes of specimens with different undulating heights. (a) B-5. (b) B-10. (c) B-15. (d) B-20. (e) B-30.

Figure 5 shows the nephogram of the shear strain field after the failure of the specimen. It can be seen that the shear strain (shear stress) concentration area is mainly in the joint contact surface along the shear direction (shear from right to left), and the crack initiation position also appears in the serrated surface of the shear stress concentration area. With the increase of the joint height, the fracture patterns become more and more complex.

3.2. Analysis of Shear Force-Displacement Curve. Figure 6 shows the relationship between shear load and shear displacement of jointed specimens with different undulation height. It can be seen that, with the increase of shear displacement, the shear load increases continuously due to the interlocking effect of serrated surface, until it suddenly decreases due to sliding or fracture of serrated surface. Finally, the shear load is stable due to friction. With the increase of the fluctuation height, the peak shear load presents fluctuation. The shear strength of the specimens with joint height of $5 \mathrm{~mm}$ is significantly lower than that of other specimens. This is because the shear failure mode of the specimen with the joint height of $5 \mathrm{~mm}$ is sliding along the joint surface.

\section{Discussion}

4.1. Shear Strain Evolutions. The ratio of shear load to peak load is defined as load level. Figure 7 shows the shear strain evolution process of the jointed specimen with undulating height of $5 \mathrm{~mm}$. It can be seen that there is no obvious deformation of the specimen when a load level of $10 \%$ is applied. When a load level of $20 \%$ is applied, small deformation occurs in the middle region of the joint surface. Then, with the increasing of the applied load, the strain in the middle of the joint surface gradually increases. When the applied load reaches a load level of 70\%, more serrated parts of the joint surface show deformation and failure. Until the load level reaches $100 \%$, all the serrated parts of the joint are destroyed. On the whole, the deformation on the left side of the jointed specimen is more obvious, and the damage degree decreases from left to right. Figure 8 shows the evolution process of the maximum shear strain of the jointed specimen with undulating height of $5 \mathrm{~mm}$. It can be seen that the maximum shear strain of the jointed specimen increases slowly with the increase of the load level, and the maximum shear strain changes a little within the load level of $40 \%-$ $80 \%$, indicating that the growth of the maximum shear strain is relatively gentle at this time. The maximum shear load increases rapidly until a load level of $90 \%$ is applied, which indicates that the jointed specimen has a rapid failure.

Figure 9 shows the evolution process of shear strain of jointed specimen with undulating height of $30 \mathrm{~mm}$. It can be found that when the load level of $10 \%-80 \%$ is applied, the distribution of strain field is relatively scattered, and there is no obvious strain concentration phenomenon in the serrated surface. When the loading level reaches $90 \% \sim 100 \%$, the shear deformation and failure of the specimen increase instantaneously, and the obvious strain concentration area appears at the serrated interface, which is mainly distributed at the serrated joint inclined to the right.

Figure 10 shows the evolution process of the maximum shear strain of the jointed specimen with undulating height of $30 \mathrm{~mm}$. When the load level is lower than $80 \%$, the maximum shear strain of the jointed specimen with undulating height of $30 \mathrm{~mm}$ is very small and almost unchanged. It shows that the jointed specimen has a strong ability to resist deformation and failure under external force at the initial stage of shear. When applied to a load level of $80 \%$, the maximum shear strain of the joint specimen increases rapidly with the continuous increase of the load level, and the jointed specimen rapidly fails under the action of shear load.

Figure 11 shows the comparison curves of maximum shear strain evolution process of jointed specimens under different undulating heights. It can be seen that when the load level is lower than $70 \%$, the maximum shear strain change of each undulating height is not very large. For the specimens with undulating height of $15 \mathrm{~mm}$, the maximum shear strain begins to increase significantly at the load level of $70 \%-80 \%$. At this time, the maximum shear strain of jointed specimens with other undulating heights still keeps a low amplitude growth trend. After the applied load level reaches $80 \%$, the maximum shear strain of all the joints with undulating height will increase rapidly with the continuous increase of the load level. The fastest growth rate is the jointed specimen with $10 \mathrm{~mm}$ undulation height, and the growth rate of other jointed specimens with undulating height is relatively similar.

4.2. Analysis of Deformation and Failure Modes. Figure 12 shows the typical development process of shear failure of jointed specimens with undulating height of $5 \mathrm{~mm}$. It can be seen that joint I first cracks from the middle of the left side 


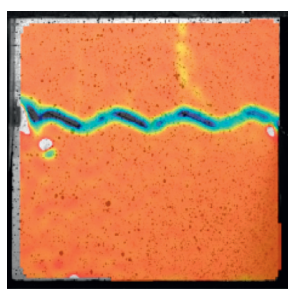

(a)

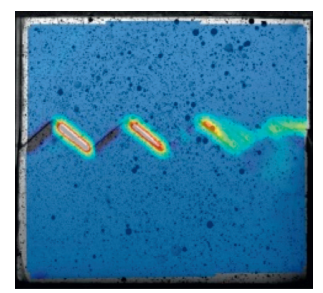

(b)

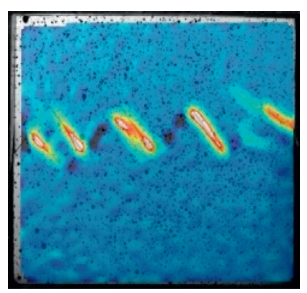

(c)

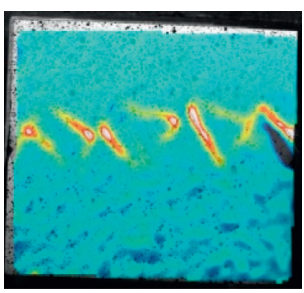

(d)

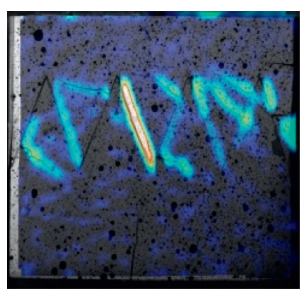

(e)

Figure 5: Shear strain field with different undulating heights. (a) B-5. (b) B-10. (c) B-15. (d) B-20. (e) B-30.

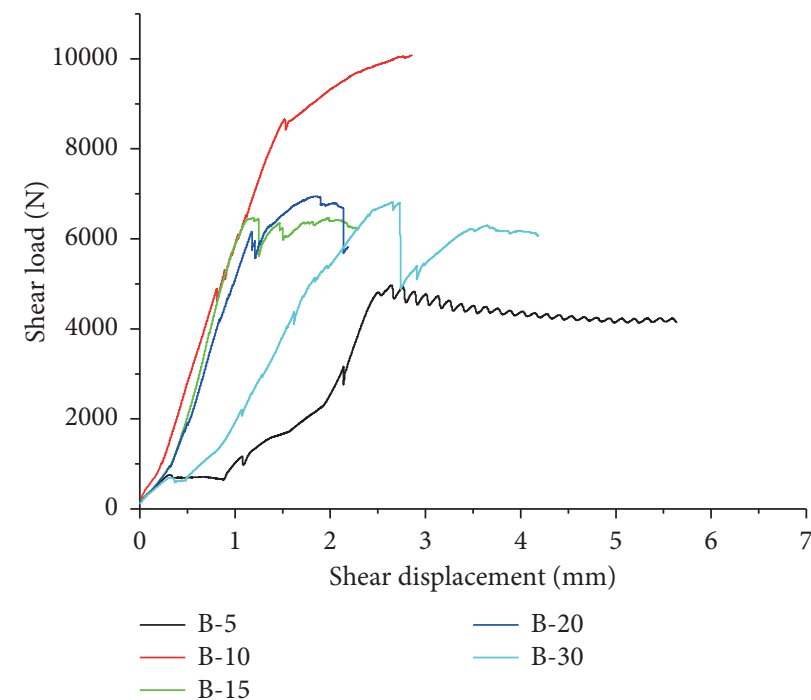

FiguRE 6: Shear mechanical properties of different undulating height models.

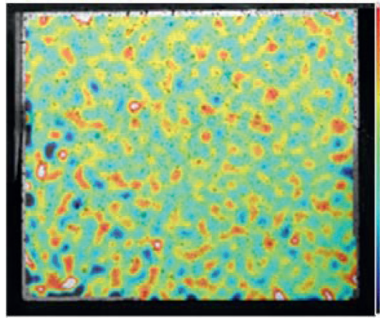

(a)

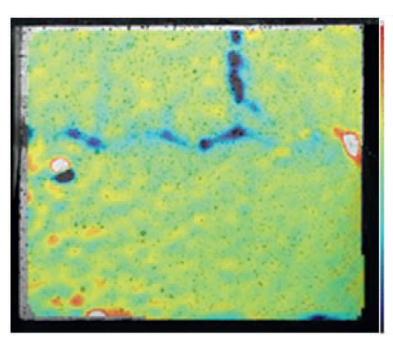

(d)

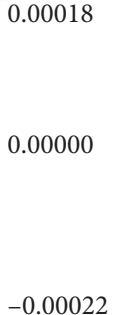

$-0.00022$

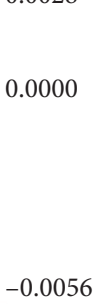

$-0.0056$

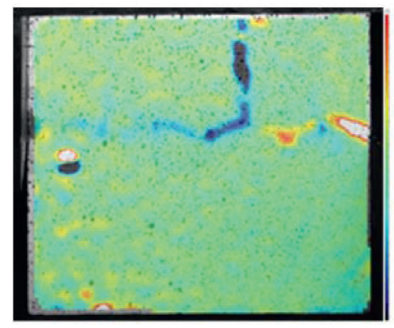

(b)

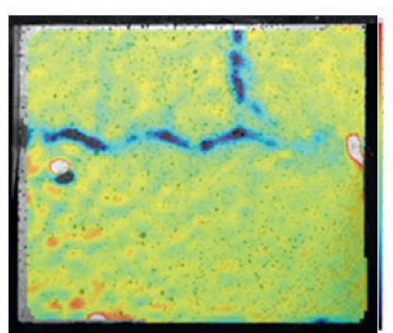

(e)

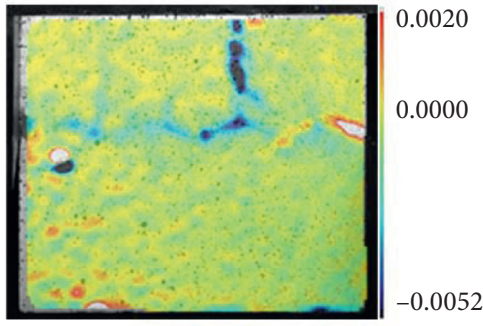

(c)

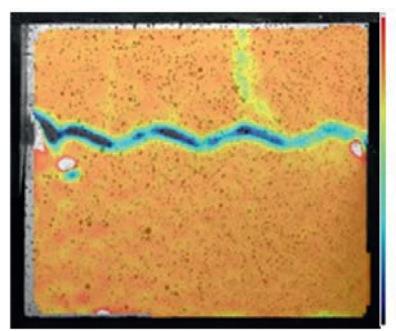

0.004

0.000 0.0000

$-0.0070$

(f)

FiguRE 7: Shear strain evolution of jointed specimens (B-5). (a) Load level of 10\%. (b) Load level of 30\%. (c) Load level of 50\%. (d) Load level of $70 \%$. (e) Load level of $90 \%$. (f) Load level of $100 \%$.

and then continues to open up along the middle part of the left side to form a macrocrack. In the middle to the left, it experienced the process of fracture initiation and opening.
Joint II starts to crack upward from the middle of the left side, and the crack initiation type is mainly tensile failure. Joint IV began to crack at the right lower tip and finally 


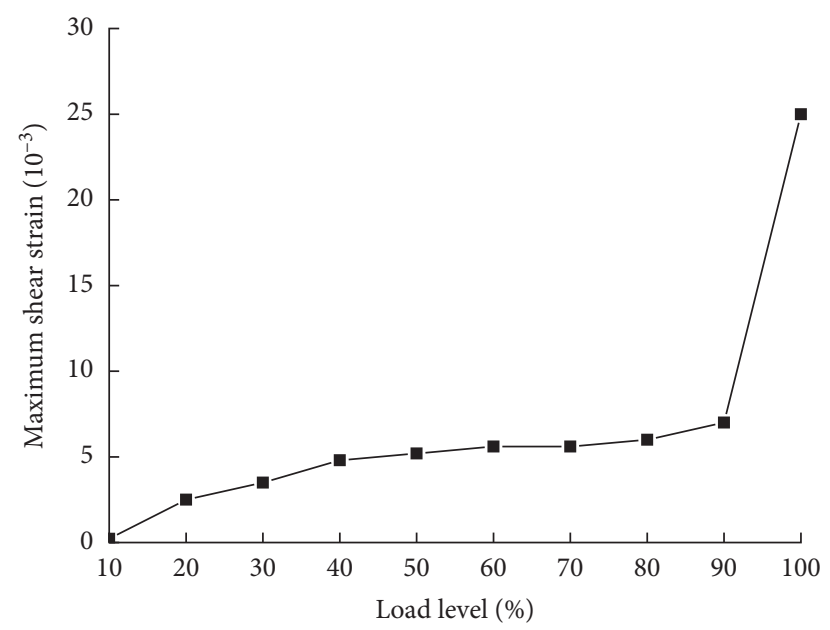

Figure 8: Evolution of maximum shear strain (B-5).
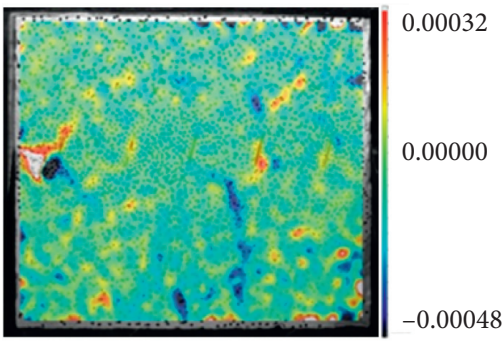

(a)

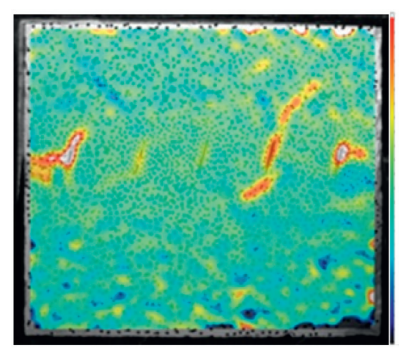

(d)
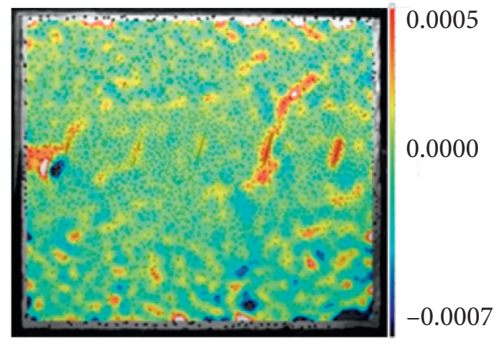

(b)

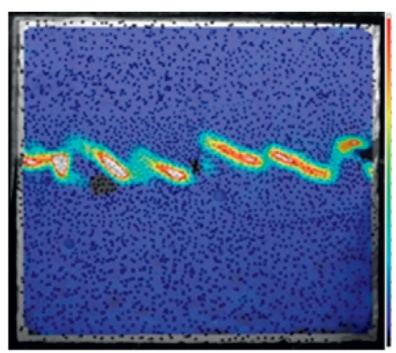

(e)

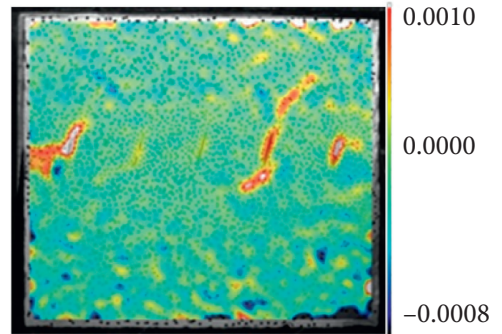

(c)

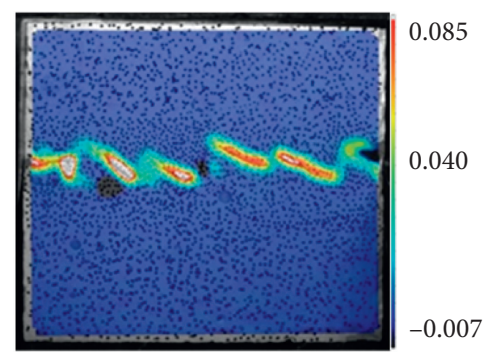

(f)

FiguRE 9: Shear strain evolution of jointed specimens (B-30). (a) Load level of 10\%. (b) Load level of 30\%. (c) load level of 50\%. (d) Load level of $70 \%$. (e) Load level of $90 \%$. (f) Load level of $100 \%$.

fractured. After the initiation of the crack, the open crack gradually penetrates and finally forms a more obvious macrocrack. Joint III starts to crack upward in the middle of the left side, and the crack initiation type is tension crack.

Figure 13 shows the typical development process of shear failure of jointed specimens with undulating height of $10 \mathrm{~mm}$. Joint IV mainly cracks from two positions: one was vertically extended from the right edge to the tip, and the other was from the lower quarter of the left side to the upper left side. With the continuous propagation of the crack, an open crack is formed and extends horizontally to the right along the left middle.

Figure 14 shows the typical development process of shear failure of jointed specimens with undulating height of $15 \mathrm{~mm}$. Joint I mainly cracks from the middle left to the right and then extends to the bottom right. Joint IV mainly opens from four positions, including the left horizontal opening from the right edge, 45 degrees opening from the right edge to the middle tip, 30 degrees opening from the middle tip to the middle of joint III, and horizontal opening to the right at one-third of the left side. Joint II mainly cracks from the left quarter to the right and then extends to the bottom, forming an open crack.

Figure 15 shows the typical development process of shear failure of joint specimens with undulating height of $20 \mathrm{~mm}$. It can be found that joint II cracks from the middle of the left to the upper left and the lower right. Joint I starts to crack from the left middle to the right and then extends to the bottom of serration until the crack opens. Joint III cracks horizontally to the left from one-third of the left tip and then extends to the tip of joint III to form an open crack. The joint IV starts to crack from the middle of the left side to the lower 


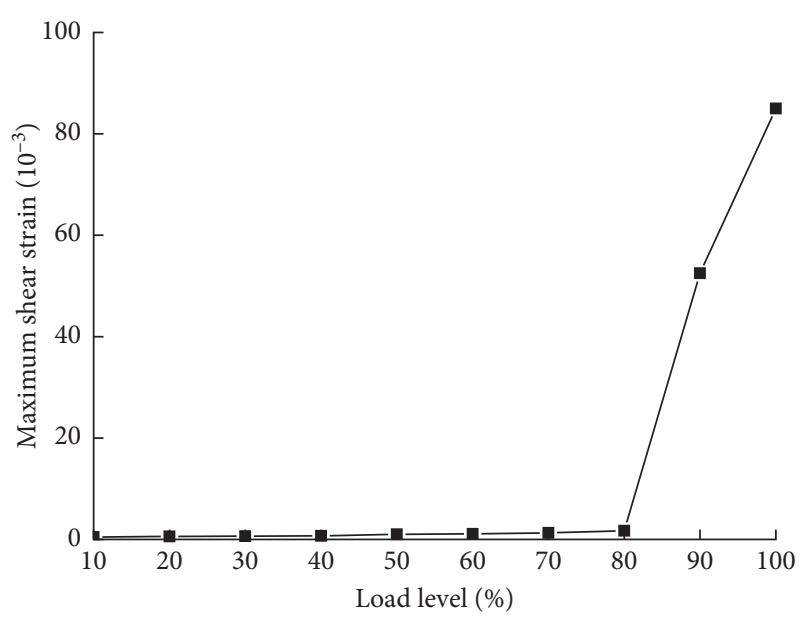

FIgURe 10: Evolution of maximum shear strain (B-30).

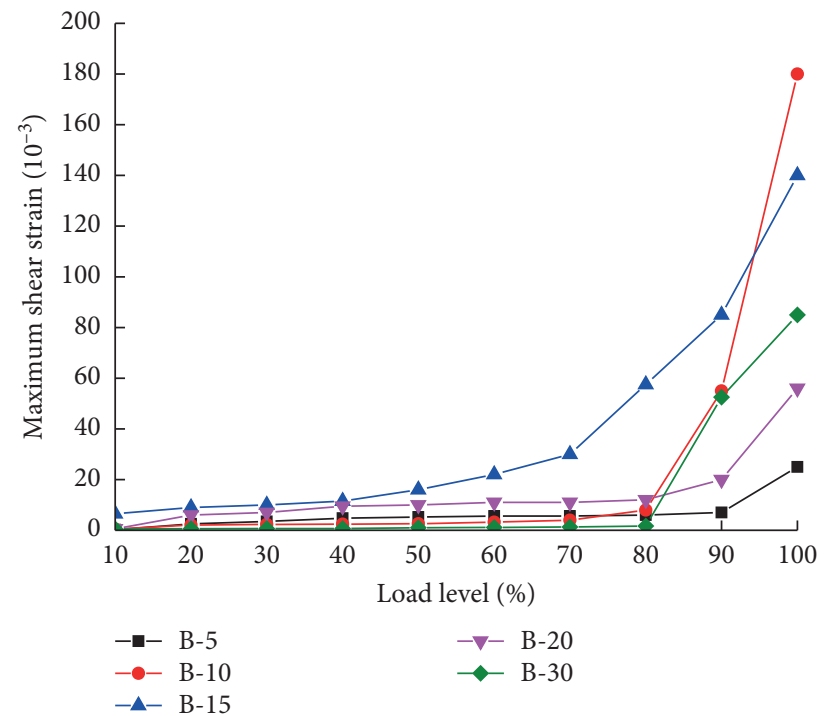

FIGURE 11: Evolution of maximum shear strain of jointed specimens with different undulating heights.

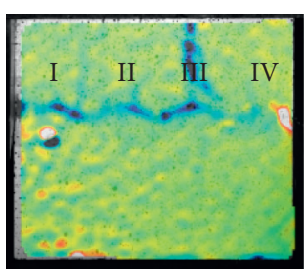

(a)

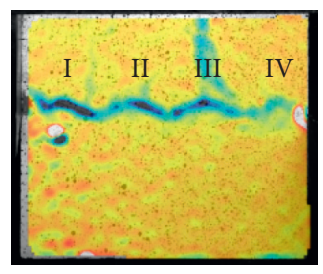

(b)

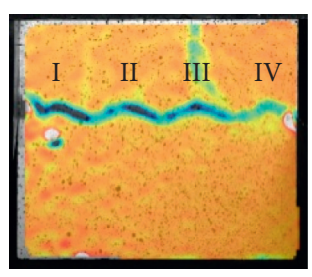

(c)

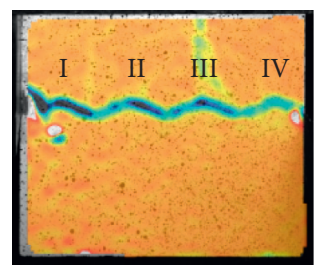

(d)

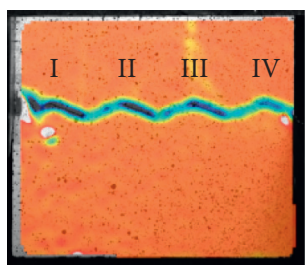

(e)

Figure 12: Typical development process of shear failure of jointed specimens (B-5).

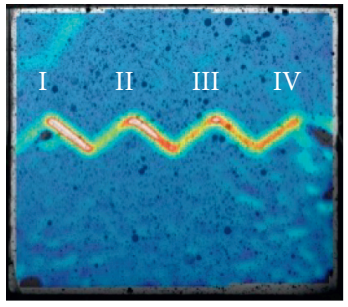

(a)

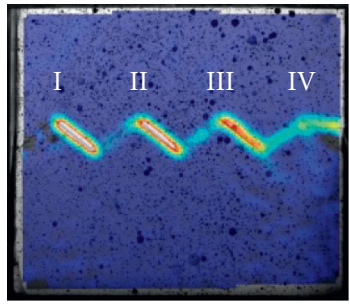

(b)

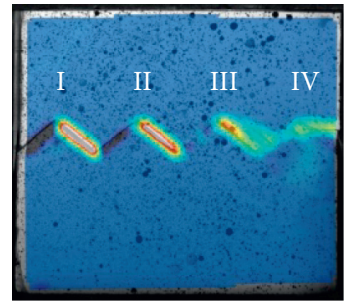

(c)

Figure 13: Typical development process of shear failure of jointed specimens (B-10). 


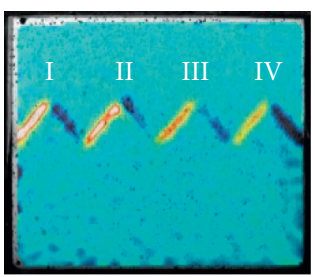

(a)

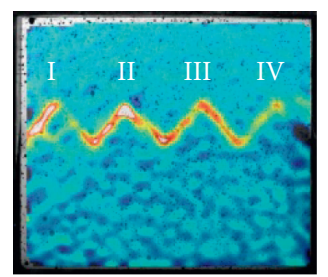

(b)

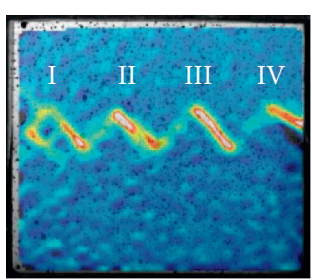

(c)

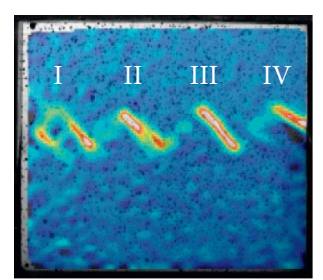

(d)

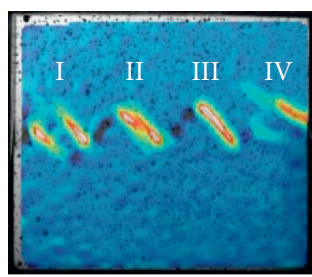

(e)

Figure 14: Typical development process of shear failure of jointed specimens (B-15).

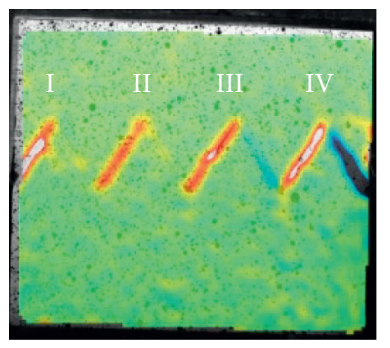

(a)

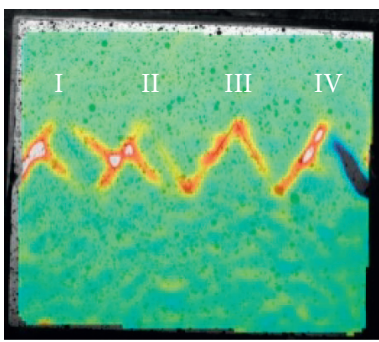

(b)

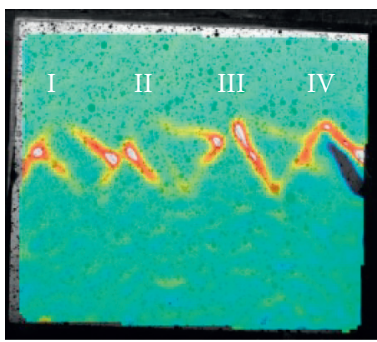

(c)

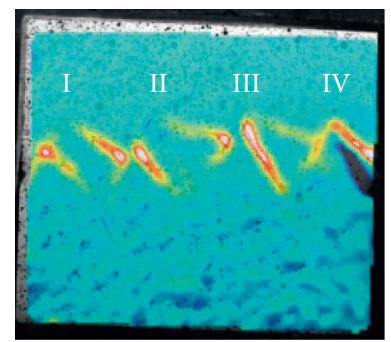

(d)

Figure 15: Typical development process of shear failure of jointed specimens (B-20).

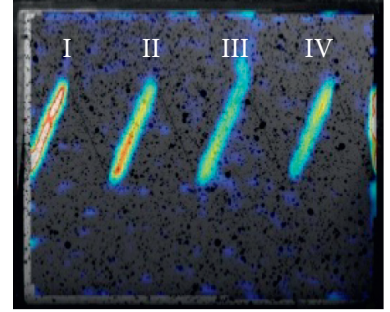

(a)

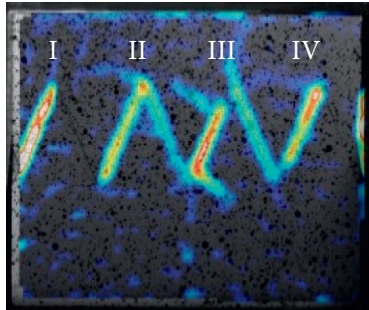

(b)

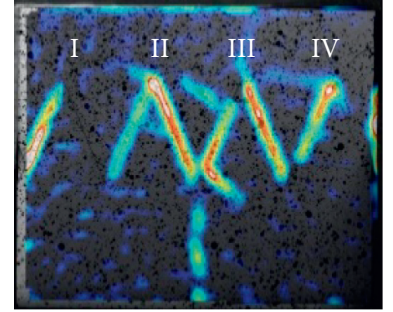

(c)

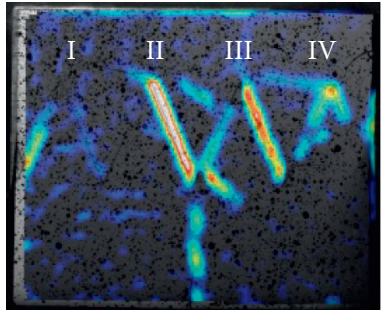

(d)

Figure 16: Typical development process of shear failure of jointed specimens (B-30).

right and then opens to the lower right along the middle of the left side, 15 degrees up to the left along the quarter of the left tip, and 45 degrees down to the right along the tip.

Figure 16 shows the typical development process of shear failure of joint specimens with undulating height of $30 \mathrm{~mm}$. It can be seen that joint I starts to crack from the bottom of the left side and then extends to the bottom end of the right side. The crack starts from the left middle part of joint II to the left and up to the left at one-third of joint III at the same time, and then joints II and III are connected, and the left one-third of joint IV is connected to the joint, and the crack opens to form a macrocrack.

From the above analysis, it is found that the fluctuation height has a significant effect on the shear strain evolution of the joint specimens. Due to the interlocking effect between the serrated surfaces, the shear load first increases and then suddenly decreases with the increase of shear displacement until the serrated surface slips or breaks. Then, the shear load tends to be stable due to the friction between the serrated surfaces. With the increase of undulating height, the peak shear load increases with fluctuation. When the undulating height is $5 \mathrm{~mm}$, the failure of the specimen is dominated by the rock sliding along prefabricated joints. When the undulating height is larger than $10 \mathrm{~mm}$, the shear fracture of the rock becomes dominant. With the increase of the undulating height, more penetrating cracks perpendicular to the preexisting joints appear between the serrated surfaces, and the shear fracture phenomenon is more obvious.

\section{Conclusions}

In this paper, the experimental study of rock mass with penetrative joints was carried out, and the shear mechanical properties of the jointed specimen under different undulation heights were discussed. Based on the DIC technology, the shear strain field of the jointed specimen during shear tests was monitored in real time. The research results will provide an important experimental reference for revealing the mechanism of shear crack initiation, propagation, and instability of jointed rock mass. The main conclusions were as follows: 
(1) Different joint undulation heights correspond to different shear strain evolution processes. The fluctuation height has a significant effect on the variation of maximum shear strain. The test results show that the failure of the specimen is closely related to the fluctuation height of the structural plane. When the undulating height is low, fracture and tensile failure are the main failure modes. With the increase of the undulating height, the tension shear failure is gradually dominant.

(2) With the increase of shear load, the maximum shear strain of the jointed specimens with different undulating heights first increases slowly and then increases rapidly. It shows that the maximum shear strain of each specimen increases slightly with the increase of shear load before the load level of $70 \%$. When it reaches $80 \%$ of the load level, the maximum shear strain increases rapidly with the increase of shear load.

(3) When the undulating height is $5 \mathrm{~mm}$, the failure of the specimen is dominated by the rock sliding along prefabricated joints. When the undulating height is larger than $10 \mathrm{~mm}$, the shear fracture of the rock becomes dominant. With the increase of the undulating height, more penetrating cracks perpendicular to the preexisting joints appear between the serrated surfaces, and the shear fracture phenomenon is more obvious.

\section{Data Availability}

The experimental data used to support the findings of this study are included within the article.

\section{Conflicts of Interest}

The authors declare that there are no conflicts of interest regarding the publication of this paper.

\section{Acknowledgments}

This research was funded by the Fundamental Research Funds for the Central Universities (no. FRF-TP-18-015A3).

\section{References}

[1] S. Dong, W. Feng, Y. Yin, R. Hu, H. Dai, and G. Zhang, "Calculating the permanent displacement of a rock slope based on the shear characteristics of a structural plane under cyclic loading," Rock Mechanics and Rock Engineering, vol. 53, no. 10, pp. 4583-4598, 2020.

[2] F. Feng, X. Li, J. Rostami, and D. Li, "Modeling hard rock failure induced by structural planes around deep circular tunnels," Engineering Fracture Mechanics, vol. 205, pp. 152174, 2019.

[3] J. Liu, Y. Chen, W. Wan, J. Wang, and X. Fan, "The influence of bedding plane orientation on rock breakages in biaxial states," Theoretical and Applied Fracture Mechanics, vol. 95, pp. 186-193, 2018.
[4] E. T. Brown, "Strength of models of rock with intermittent joints," Journal of Soil Mechanics \& Foundations Divisions, vol. 96, no. 6, 1970.

[5] E. Gerolymatou and T. Triantafyllidis, "Shearing of materials with intermittent joints," Rock Mechanics and Rock Engineering, vol. 49, no. 7, pp. 2689-2700, 2016.

[6] Q. Guo, J. Pan, M. Cai, and Y. Zhang, "Analysis of progressive failure mechanism of rock slope with locked section based on energy theory," Energies, vol. 13, no. 5, p. 1128, 2020.

[7] Q. Guo, J. Pan, M. Cai, and Y. Zhang, "Investigating the effect of rock bridge on the stability of locked section slopes by the direct shear test and acoustic emission technique," Sensors, vol. 20, no. 3, p. 638, 2020.

[8] J. Pan, Z. Gao, and F. Ren, "Effect of strength criteria on surrounding rock of circular roadway considering strain softening and dilatancy," Journal of the China Coal Society, vol. 43, no. 12, pp. 3293-3301, 2018.

[9] S. Bandis, A. C. Lumsden, and N. R. Barton, "Experimental studies of scale effects on the shear behaviour of rock joints," International Journal of Rock Mechanics and Mining Sciences \& Geomechanics Abstracts, vol. 18, no. 1, pp. 1-21, 1981.

[10] H. Jalalifar and N. Aziz, "Experimental and 3D numerical simulation of reinforced shear joints," Rock Mechanics and Rock Engineering, vol. 43, no. 1, pp. 95-103, 2010.

[11] E. Z. Lajtai, "Shear strength of weakness planes in rock," International Journal of Rock Mechanics and Mining Sciences \& Geomechanics Abstracts, vol. 6, no. 5, pp. 499-515, 1969.

[12] E. Z. Lajtai, "Strength of discontinuous rocks in direct shear," Géotechnique, vol. 19, no. 2, pp. 218-233, 1969.

[13] C. Gehle and H. K. Kutter, "Breakage and shear behaviour of intermittent rock joints," International Journal of Rock Mechanics and Mining Sciences, vol. 40, no. 5, pp. 687-700, 2003.

[14] W. Zhu, M. Pang, C. Tang et al., "Numerical simulation on failure process of pre-cracked rock disk under dynamic loading," Chinese Journal of Underground Space and Engineering, vol. 6, pp. 856-858, 2005.

[15] D. Yang, D. Zhang, S. Niu et al., "Uniaxial compression experimental study on crack propagation process and macroscopic failure mode of pre fractured fine sandstone," Journal of Mining and Safety Engineering, vol. 36, no. 4, pp. 786-793, 2019.

[16] R. Yang, W. Li, S. Fang et al., "Experimental study on impact dynamic characteristics of layered composite rock mass," Chinese Journal of Rock Mechanics and Engineering, vol. 38, no. 9, pp. 1747-1757, 2019.

[17] C. Xia, Y. Song, Z. Tang et al., "Particle flow numerical simulation for shear behavior of rough joints," Chinese Journal of Rock Mechanics and Engineering, vol. 31, no. 8, pp. 1545-1552, 2012, in Chinese.

[18] M. S. Asadi, V. Rasouli, and G. A. Barla, "A bonded particle model simulation of shear strength and asperity degradation for rough rock fracture," Rock Mechanics and Rock Engineering, vol. 45, pp. 649-675, 2012.

[19] M. Huang, "Study on the failure mechanism of multiple cracks in rock," Chinese Journal of Rock Mechanics and Engineering, vol. 3, p. 423, 2001.

[20] C. Peng, Q. Guo, Z. Yan, M. Wang, and J. Pan, "Investigating the failure mechanism of jointed rock slopes based on discrete element method," Advances in Civil Engineering, vol. 2020, Article ID 8820158, 19 pages, 2020.

[21] Q. Guo, Z. Dong, M. Cai, F. Ren, and J. Pan, "Safety evaluation of underground caverns based on Monte Carlo method," Mathematical Problems in Engineering, vol. 2020, Article ID 7214720, 7 pages, 2020. 
[22] X. Xi, X. Wu, Q. Guo, and M. Cai, "Experimental investigation and numerical simulation on the crack initiation and propagation of rock with pre-existing cracks," IEEE Access, vol. 8, pp. 129636-129644, 2020.

[23] J.-W. Park and J.-J. Song, "Numerical simulation of a direct shear test on a rock joint using a bonded-particle model," International Journal of Rock Mechanics and Mining Sciences, vol. 46, no. 8, pp. 1315-1328, 2009.

[24] M. Bahaaddini, "Effect of boundary condition on the shear behaviour of rock joints in the direct shear test," Rock Mechanics and Rock Engineering, vol. 50, no. 5, pp. 1141-1155, 2017.

[25] X. Xi, Z. Yin, S. Yang, and C.-Q. Li, "Using artificial neural network to predict the fracture properties of the interfacial transition zone of concrete at the meso-scale," Engineering Fracture Mechanics, vol. 242, Article ID 107488, 2021.

[26] J. P. Seidel and C. M. Haberfield, "The application of energy principles to the determination of the sliding resistance of rock joints," Rock Mechanics and Rock Engineering, vol. 28, no. 4, pp. 211-226, 1995.

[27] T.-H. Kwon, E.-S. Hong, and G.-C. Cho, "Shear behavior of rectangular-shaped asperities in rock joints," KSCE Journal of Civil Engineering, vol. 14, no. 3, pp. 323-332, 2010.

[28] M. Chen, "Study on failure mechanical characteristics and anchorage control mechanism of intermittent jointed rock mass," Dissertation, China University of Mining and Technology, Xuzhou, China, 2019.

[29] W. H. Peters and W. F. Ranson, "Digital imaging techniques in experimental stress analysis," Optical Engineering, vol. 21, no. 3, pp. 427-431, 1982.

[30] J. Pan, X. Wu, Q. Guo, X. Xi, and M. Cai, "Uniaxial experimental study of the deformation behavior and energy evolution of conjugate jointed rock based on $\mathrm{AE}$ and DIC methods," Advances in Civil Engineering, vol. 2020, Article ID 8850250, 16 pages, 2020.

[31] F. Ren, L. Zhang, X. Wu, and W. Liu, "Experimental study on shear failure characteristics of jointed rock mass based on direct shear tests and digital image correction techniques," Advances in Civil Engineering, vol. 2021, Article ID 6684859, 16 pages, 2021.

[32] Y. Tang, S. Okubo, J. Xu, and S. Peng, "Progressive failure behaviors and crack evolution of rocks under triaxial compression by $3 \mathrm{D}$ digital image correlation," Engineering Geology, vol. 249, pp. 172-185, 2019.

[33] D. Li, Q. Zhu, Z. Zhou, X. Li, and P. G. Ranjith, "Fracture analysis of marble specimens with a hole under uniaxial compression by digital image correlation," Engineering Fracture Mechanics, vol. 183, pp. 109-124, 2017.

[34] S. Miao, P.-Z. Pan, Z. Wu, S. Li, and S. Zhao, "Fracture analysis of sandstone with a single filled flaw under uniaxial compression," Engineering Fracture Mechanics, vol. 204, pp. 319-343, 2018.

[35] W.-W. Ji, P.-Z. Pan, Q. Lin, X.-T. Feng, and M.-P. Du, "Do disk-type specimens generate a mode II fracture without confinement?" International Journal of Rock Mechanics and Mining Sciences, vol. 87, pp. 48-54, 2016.

[36] H. Su, H. Jing, L. Yu, Q. Yin, and G. Han, "Mode I fracture behaviour of sandstone after heat treatment," Géotechnique Letters, vol. 7, no. 1, pp. 47-52, 2017.

[37] S. Miao, P.-Z. Pan, P. Yu, S. Zhao, and C. Shao, "Fracture analysis of Beishan granite after high-temperature treatment using digital image correlation," Engineering Fracture Mechanics, vol. 225, Article ID 106847, 2020. 